\title{
PREDIKSI JUMLAH KUNJUNGAN WISATAWAN MANCANEGARA KE INDONESIA
}

\author{
Aida Meimela
}

Badan Pusat Statistik Provinsi Sumatera Utara, Medan, Indonesia, Email: aida.mey@bps.go.id Mahasiswa Magister Statistik Terapan Universitas Padjadjaran, Bandung, Indonesia

\begin{tabular}{|c|c|}
\hline & ABSTRAK \\
\hline $\begin{array}{l}\text { Histori Artikel } \\
\\
\text { Submitted: } \\
\text { 5 Desember } 2020 \\
\text { Reviewed: } \\
\text { 10 Desember } 2020 \\
\text { Accepted: } \\
\text { 15 Desember } 2020 \\
\text { Published: } \\
\text { 15 Mei } 2021\end{array}$ & $\begin{array}{l}\text { Kementerian Pariwisata dan Ekonomi Kreatif menargetkan jumlah } \\
\text { kunjungan wisatawan mancanegara ke Indonesia sebanyak } 17 \text { juta } \\
\text { kunjungan di tahun 2020. Akan tetapi, jumlah kunjungan wisatawan } \\
\text { mancanegara mengalami penurunan secara kumulatif (Januari- Juli } \\
\text { 2020) sebesar } 64,64 \text { persen dibandingkan dengan periode yang sama di } \\
\text { tahun 2019. Berdasarkan kondisi tersebut maka sangatlah penting untuk } \\
\text { melakukan prediksi yang akurat guna melihat apakah target tersebut } \\
\text { akan tercapai atau tidak di masa mendatang. Salah satu metode prediksi } \\
\text { yang dipakai adalah Seasonal ARIMA (Autoregressive Integrated } \\
\text { Moving Average). Dari model yang terbentuk, diprediksi jumlah } \\
\text { kunjungan wisatawan mancanegara di tahun diprediksi akan melewati }\end{array}$ \\
\hline
\end{tabular}

Kata Kunci: Pariwisata, wisatawan, ARIMA, deret waktu

\section{PREDICT THE NUMBER OF FOREIGN TOURIST'S VISIT INDONESIA}

\begin{abstract}
In 2020 the Ministry of Tourism and Creative Economy has targeted the number of foreign tourists visiting Indonesia as many as 17 million visits. However, the number of foreign tourist visits decreased cumulatively (January-July 2020) by 64.64 percent compared to the same period in 2019. Based on these conditions, it is significant to make accurate predictions to see if the target will be achieved or not in the future. One of the prediction methods used is Seasonal ARIMA (Autoregressive Integrated Moving Average). This model predicted the predictable number of foreign tourists visit in 2020 forecast to pass the target.
\end{abstract}

Keywords : Tourism, tourists, ARIMA, time series 


\section{PENDAHULUAN}

Dalam Rencana Pembangunan Jangka Menengah Nasional (RPJMN) 2020-2024 tertuang bahwa target konstribusi pariwisata terhadap Pendapatan Domestik Bruto (PDB) Indonesia adalah 5,5 persen di tahun 2024 (Kementerian PPN/Bappenas, 2019). Untuk merealisasikan hal tersebut, Kementerian Pariwisata dan Ekonomi Kreatif menargetkan jumlah kunjungan wisatawan mancanegara ke Indonesia sebanyak 17 juta kunjungan di tahun 2020 (Kontan, 2020).

Akan tetapi, pandemi covid-19 yang dimulai sejak akhir Desember 2019 menimbulkan krisis sosial dan ekonomi hampir diseluruh negara di dunia tidak terkecuali Indonesia. Salah satu sektor yang terdampak adalah sektor pariwisata. Hal ini terlihat dari jumlah kunjungan wisatawan mancanegara yang mengalami penurunan secara kumulatif (Januari- Juli 2020) sebesar 64,64 persen dibandingkan dengan periode yang sama di tahun 2019 (BPS, 2020).

Berdasarkan kondisi tersebut maka sangatlah penting untuk melakukan prediksi yang akurat guna melihat apakah target tersebut akan tercapai atau tidak di masa mendatang. Sehingga dapat dirumuskan kebijakankebijakan yang diperlukan untuk mencapai target tersebut. Prediksi jumlah kunjungan wisatawan mancanegara tidak hanya dibutuhkan oleh pemerintah saja akan tetapi juga oleh pihak swasta. Bagi pihak swasta bertujuan untuk merancang infrastruktur pariwisata seperti hotel dan rencana pengembangan transportasi. Sementara bagi pemerintah seperti perencanaan jumlah penerbangan pesawat, fasilitas untuk wisatawan dan juga sumber daya manusia yang dibutuhkan (Chang \& Liao, 2010).

\section{LITERATUR REVIEW}

Sektor pariwisata merupakan salah satu prioritas pembangunan saat ini. Wisatawan mancanegara adalah setiap orang yang berasal dari negara lain yang melakukan perjalanan ke Indonesia melalui pelabuhan internasional, baik melalui bandar udara, pelabuhan laut maupun darat. Dimana tujuan utamanya adalah selain bekerja dan lamanya kunjungan kurang dari satu tahun (BPS, 2018). Salah satu metode peramalan yang umum digunakan adalah ARIMA (Autoregressive Integrated Moving Average).

Model ini mampu melakukan peramalan menggunakan data masa lalu dan sekarang. Jika dalam model ARIMA ditemukan pola musiman maka model yang digunakan adalah Seasonal Autoregressive Integrated Moving Average (Seasonal ARIMA). Model ini dapat mengatasi data yang tidak stasioner dan stasioner dengan secara bersamaan baik yang memiliki pola musiman maupun yang tidak (Chang \& Liao, 2010). Kumar dan Sharma melakukan penelitian tentang arus wisatawan di Asia Tenggara juga menggunakan SARIMA dikarenakan keakuratannya lebih tinggi dibanding ARIMA dan Holts Winters (Kumar \& Sharma, 2016). Hasil penelitian lainnya tentang peramalan kedatangan wisatawan di Zimbabwe juga menunjukkan bahwa metode SARIMA merupakan model yang baik dibanding model lainnya (Makoni \& Chikobvu, 2018).

\section{METODE}

Variabel yang digunakan adalah jumlah kunjungan wisatawan mancanegara ke Indonesia dengan periode waktu bulanan mulai Januari 2008 sampai Desember 2019 yang bersumber dari Badan Pusat Statistik. Penelitian ini data akan dibagi menjadi dua yakni data in sample dan data out sample. Data in sample mulai Januari 2008 Desember 2018 yakni sebanyak 132 observasi. Sementara itu untuk data out sample mulai Januari - Desember 2019 sebanyak 12 observasi.

\section{Seasonal Autoregressive Integrated Moving Average (Seasonal ARIMA)}

Seasonal Autoregressive Integrated Moving Average (Seasonal ARIMA) merupakan salah satu pengembangan dari model Autoregressive Integrated Moving Average 
(ARIMA) yang memiliki pola musiman (Box et al., 2016). Persamaan umum Seasonal ARIMA dapat dibentuk sebagai berikut (Wei, 2005):

$$
\begin{aligned}
& \Phi_{P}\left(B^{s}\right) \Phi_{p}(B)(I-B)^{d}\left(I-B^{s}\right)^{\mathrm{D}} \dot{\mathrm{Z}}_{\mathrm{t}}= \\
& \Theta_{\mathrm{q}}(\mathrm{B}) \Theta_{\mathrm{Q}}\left(\mathrm{B}^{\mathrm{s}}\right) \mathrm{a}_{\mathrm{t}}
\end{aligned}
$$

Keterangan :

$Z_{t} \quad$ : data deret waktu dengan rata-rata $\mu$

$\Phi_{p}(B)$ : persamaan polynomial AR(p)

$\Theta_{q}(B)$ : persamaan polynomial MA(q)

$\Phi_{P}\left(B^{S}\right)$ : persamaan polynomial musiman $\mathrm{AR}(\mathrm{P})$

$\Theta_{Q}\left(B^{S}\right)$ : persamaan polynomial musiman $\mathrm{MA}(\mathrm{Q})$

$(I-B)^{d}$ : operator pembeda non musiman dengan periode $\mathrm{d}$

$\left(I-B^{S}\right)^{D}$ : operator pembeda musiman dengan periode $S$

$a_{t} \quad$ : residual yang diasumsikan white noise

\section{Uji Stasioneritas}

Untuk melihat data sudah stasioner dalam rata-rata dilakukan uji Augmented Dickey Fuller (ADF). Sementara untuk melihat data sudah stasioner dalam varians melalui nilai lambda $(\lambda)$ dari Uji Box-Cox. Data stasioner dalam varians jika nilai $\lambda$ melalui nilai satu (Mulyaningsih, 2015). Agar data stasioner dalam varians maka harus dilakukan transformasi Box-Cox (Wei, 2005).

\section{Uji White Noise dan Normalitas}

Suatu data dikatakan white noise jika ratarata 0 dan varians adalah $\sigma_{\varepsilon}^{2}$ atau dituliskan dengan $\varepsilon_{t} \sim W N\left(0, \sigma_{\varepsilon}^{2}\right) \quad$ (Iwok, 2017). Uji white noise dilakukan menggunakan uji LJung Box yang dirumuskan sebagai berikut (Zakaria et al., 2012):

$$
Q=n(n+2) \sum_{k=1}^{h} \frac{r_{k}^{2}}{n-k}
$$

dimana $h$ adalah lag maksimum, n adalah jumlah observasi dan $r_{k}$ adalah autokorelasi residual pada lag ke $\mathrm{k}$. Sementara itu untuk asumsi normalitas dapat dilakukan dengan uji Saphiro Wilk karena uji ini memiliki tingkat keakuratan yang baik (Razali \& Wah, 2011).

\section{Pemilihan Model terbaik}

Untuk menentukan model mana yang akan digunakan dengan melihat nilai Akaike's Information Criterion (AIC). Akan tetapi AIC akan bias jika parameter yang digunakan pada model terlalu banyak (Wei, 2005). Kriteria pemilihan model terbaik didasarkan pada nilai AIC yang terkecil. AIC dapat dirumuskan sebagai berikut:

$$
\operatorname{AIC}(M)=n \ln \hat{\sigma}_{\alpha}^{2}+2 M
$$

$\mathrm{n}$ adalah jumlah observasi, $\hat{\sigma}_{\alpha}^{2}$ adalah varians residual dan $\mathrm{M}$ adalah banyaknya parameter dalam model.

\section{Ketepatan Prediksi}

Dalam mengukur keakuratan suatu model dapat menggunakan MAPE (Means Absolute Percentage Eror). MAPE merupakan persentase dari rata-rata harga mutlak residual pada setiap periode dibagi dengan nilai aktual pada periode tersebut. MAPE dihitung dengan rumus sebagai berikut (Brida \& Garrido, 2011):

$$
\mathrm{MAPE}=\frac{1}{n} \sum_{i=1}^{n}\left|\left(\frac{X_{I}-F_{i}}{X_{i}}\right) \times 100 \%\right|
$$

dimana $X_{i}$ adalah data aktual untuk periode i dan $F_{i}$ adalah hasil peramalan pada periode yang sama. Kriteria penghitungan MAPE yakni (Lewis, 1982):

$\begin{array}{ll}<10 \% & : \text { highly accurate forecasting } \\ 10 \%-20 \% & : \text { good forecasting } \\ 20 \%-50 \% & : \text { reasonable forecasting } \\ >50 \% & : \text { weak and inaccurate } \\ \text { predictability } & \end{array}$

\section{HASIL DAN PEMBAHASAN}

Jumlah kunjungan wisatawan mancanegara ke Indonesia paling sedikit terjadi pada Februari 2009 yakni sebanyak 421.555 kunjungan. Kondisi ini dipengaruhi oleh krisis global yang tengah melanda dunia saat itu. Sementara itu jumlah kunjungan tertinggi terjadi pada Juli 2018 yakni sebanyak 1.547.231 kunjungan. Rata-rata kunjungan 
wisman sepanjang tahun 2008 -2019 sebanyak 838.185 kunjungan.

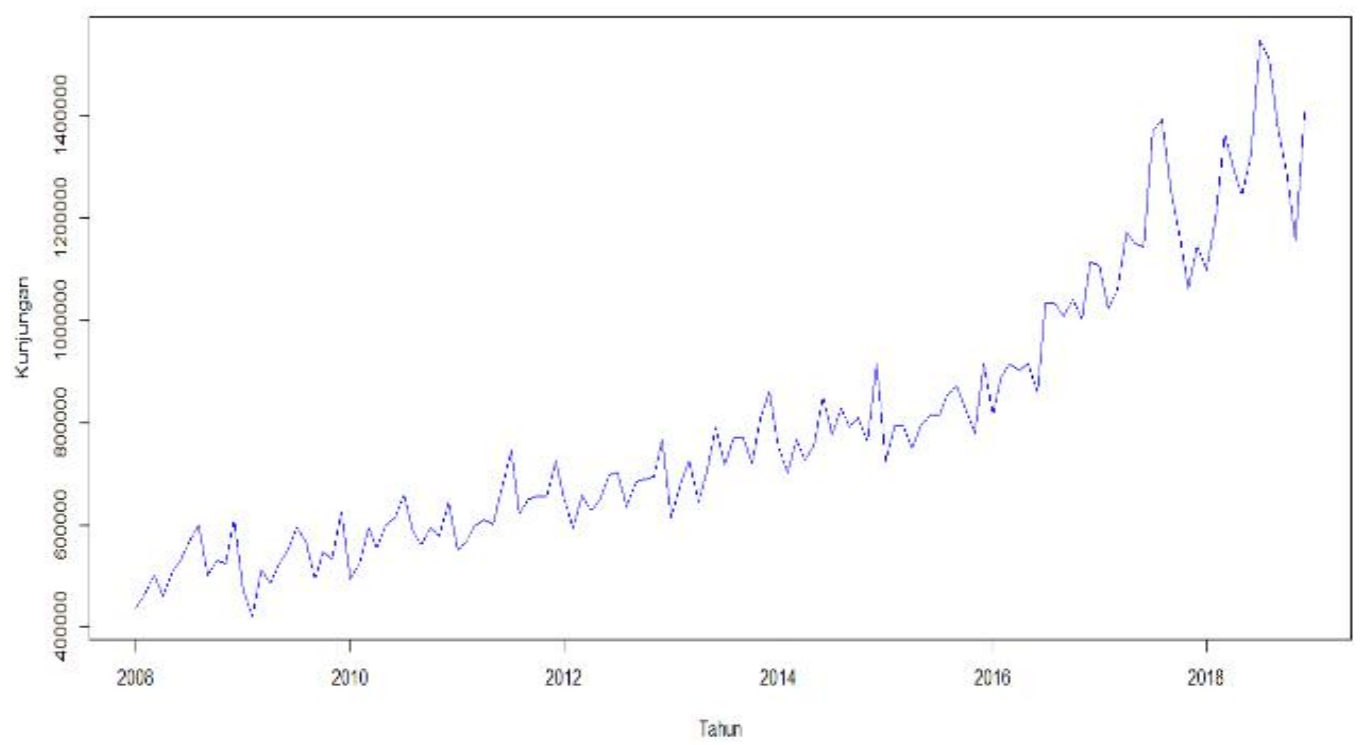

Gambar 1. Kunjungan Wisatawan Mancanegara ke Indonesia Tahun 2008-2018

\section{Uji Stasioneritas}

Uji Augmented Dicky Fuller (ADF) menunjukkan bahwa data masih mengandung unit root atau belum stasioner dalam rata-rata dimana nilai $p$-value sebesar 0,815 . Untuk mengatasi hal ini maka dilakukan differencing orde 1 . Sementara itu uji BoxCox menunjukkan nilai $\lambda=-0,0265$ yang berarti bahwa data belum stasioner dalam varians sehingga perlu dilakukan transformasi. Ketidakstasioneran data juga terlihat pada pola ACF dan PACF pada Gambar 2.

Plot ACF pada Gambar 3 menunjukkan adanya pola musiman berulang di setiap selang waktu 12 bulan. Sehingga dapat dikatakan data belum stasioner dalam musiman. Untuk mengatasi ini dilakukan differencing pada orde 12. Langkah selanjutnya adalah identifikasi model sementara Seasonal ARIMA yang dinotasikan dalam bentuk $(\mathrm{p}, \mathrm{d}, \mathrm{q})(\mathrm{P}, \mathrm{D}, \mathrm{Q})^{\mathrm{S}}$. Model Seasonal ARIMA sementara yang terbentuk adalah $(2,1,1)(0,1,1)^{12}$, $(2,1,0)(0,1,1)^{12}, \quad(1,1,1)(0,1,1)^{12}$, $(1,1,0)(0,1,1)^{12}$ dan $(0,1,1)(0,1,1)^{12}$. Untuk memperoleh model terbaik pada kelima model sementara tersebut masing-masing dilakukan evaluasi dengan melihat signifikansi parameter, uji white noise, uji normalitas dan nilai AIC nya. 



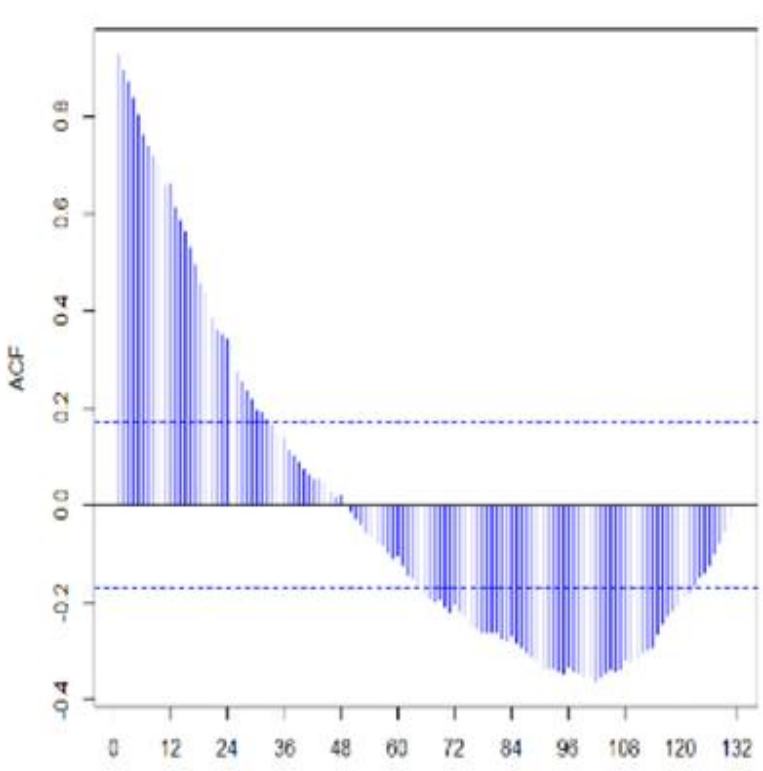

tag

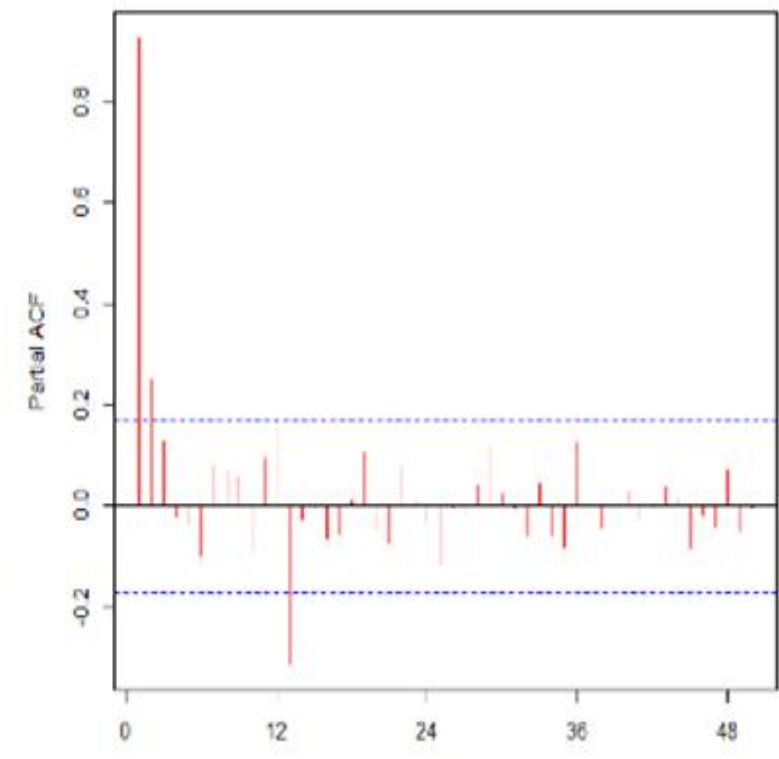

Lag

Gambar 2. Plot ACF dan PACF Jumlah Kunjungan Wisman Ke Indonesia
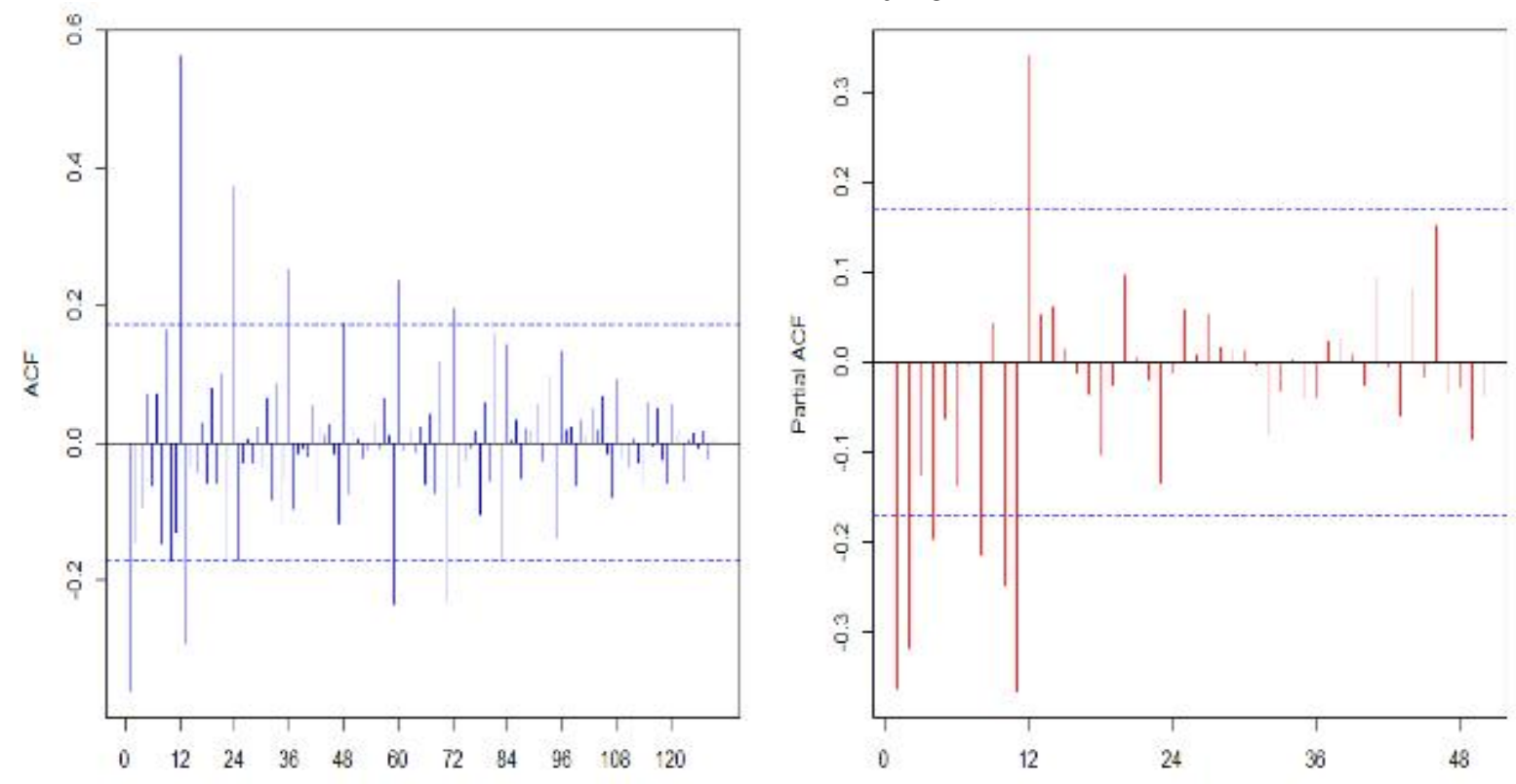

Lag

Lag

Gambar 3. Plot ACF dan PACF Setelah Transformasi dan Differencing Orde 1

Tabel 1. Evaluasi dan Uji Asumsi Model Seasonal ARIMA Dugaan

\begin{tabular}{lcccc}
\hline Model & $\begin{array}{c}\text { Signifikansi } \\
\text { Parameter } \\
\text { Model }\end{array}$ & $\begin{array}{c}\text { Residual } \\
\text { White Noise }\end{array}$ & $\begin{array}{c}\text { Residual } \\
\text { Normal }\end{array}$ & AIC \\
\hline$(2,1,1)(0,1,1)^{12}$ & Tidak & Ya & Ya & $-310,95$ \\
\hline$(2,1,0)(0,1,1)^{12}$ & Ya & Ya & Ya & $-309,51$ \\
\hline$(1,1,1)(0,1,1)^{12}$ & Tidak & Ya & Ya & $-312,80$ \\
\hline$(1,1,0)(0,1,1)^{12}$ & Ya & Tidak & Ya & $-300,36$ \\
\hline$(0,1,1)(0,1,1)^{12}$ & Ya & Ya & Ya & $-314,63$ \\
\hline
\end{tabular}

Sumber: Data primer, (2020) 
Dari Tabel 1 maka model yang memenuhi semua asumsi dan memiliki nilai AIC terkecil adalah model Seasonal ARIMA $(0,1,1)(0,1,1)^{12}$ yang dapat ditulis dalam persamaan berikut:

$$
\begin{gathered}
\dot{Z}_{t}=\dot{Z}_{t-1}+\dot{Z}_{t-12}-\dot{Z}_{t-13}+0,6645 a_{t-1}+ \\
0,4062 a_{t-12}+0,2699 a_{t-13}+a_{t}
\end{gathered}
$$

Dari persamaan yang terbentuk terlihat bahwa jumlah kunjungan wisatawan dipengaruhi oleh jumlah kunjungan wisatawan periode sebelumnya.

\section{Ketepatan Prediksi}

Nilai MAPE model Seasonal ARIMA $(0,1,1)(0,1,1)^{12}$ diperoleh sebesar 10,877 persen. Nilai ini mengindikasikan bahwa akurasi peramalan model memiliki akurasi baik (Maricar, 2019). Dengan demikian dapat dilakukan peramalan jumlah kunjungan wisman selama tahun 2020 dengan interval kepercayaan 95 persen (Tabel 2).

Hasil peramalan menunjukkan jumlah kunjungan wisman ke Indonesia pada tahun
2020 akan mencapai 20.329.410 kunjungan. Angka ini melebihi target yang dibuat oleh Kementerian Pariwisata dan Ekonomi Kreatif yakni sebesar 17 juta kunjungan.

Tabel 2. Prediksi Jumlah Kunjungan Wisman Tahun 2020

\begin{tabular}{lccc}
\hline \multicolumn{1}{c}{ Bulan } & Prediksi & $\begin{array}{c}\text { Batas } \\
\text { Atas }\end{array}$ & $\begin{array}{c}\text { Batas } \\
\text { Bawah }\end{array}$ \\
\hline Januari & 1.467 .725 & 1.184 .956 & 1.817 .972 \\
\hline Februari & 1.533 .655 & 1.226 .366 & 1.917 .941 \\
\hline Maret & 1.679 .054 & 1.330 .342 & 2.119 .171 \\
\hline April & 1.664 .824 & 1.307 .450 & 2.119 .881 \\
\hline Mei & 1.619 .558 & 1.261 .094 & 2.079 .915 \\
\hline Juni & 1.675 .331 & 1.293 .802 & 2.169 .369 \\
\hline Juli & 1.952 .287 & 1.495 .678 & 2.548 .293 \\
\hline Agustus & 1.937 .846 & 1.473 .134 & 2.529 .156 \\
\hline September & 1.778 .038 & 1.341 .483 & 2.356 .659 \\
\hline Oktober & 1.687 .981 & 1.264 .209 & 2.253 .806 \\
\hline Nopember & 1.538 .170 & 1.143 .778 & 2.068 .555 \\
\hline Desember & 1.794 .941 & 1.325 .400 & 2.430 .821 \\
\hline Sumber: Data & primer, 2020 & & \\
\hline
\end{tabular}

Sumber: Data primer, 2020

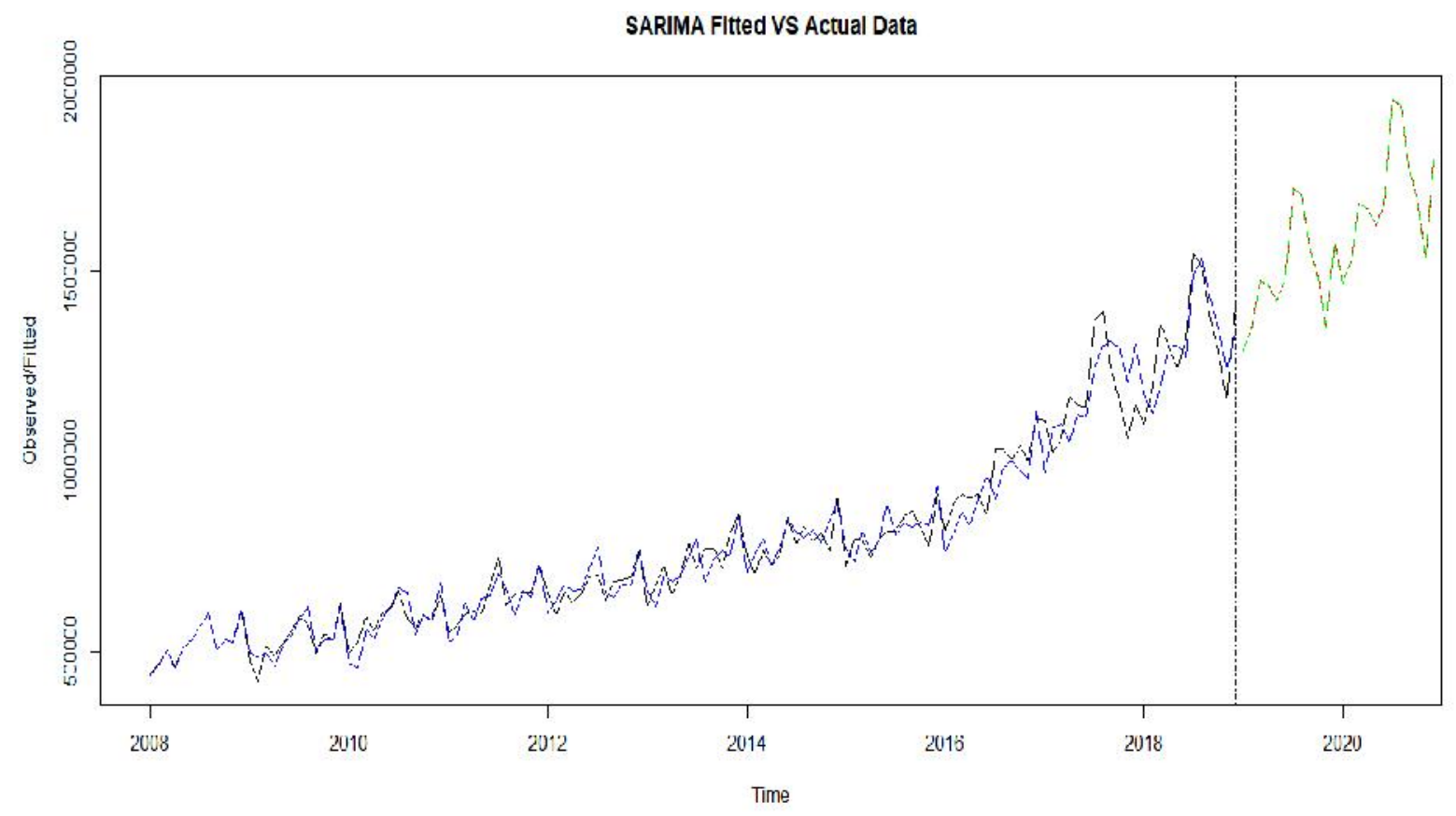

Gambar 4. Pergerakan Data Aktual dan Data dengan Model Seasonal ARIMA $(0,1,1)(0,1,1)^{12}$

Dari Gambar 4 terlihat bahwa prediksi data menggunakan model tidak begitu jauh berbeda dengan data aktual. Dimana garis yang berwana hitam adalah data aktual sedangkan garis yang berwarna biru adalah data yang menggunakan model Seasonal
ARIMA yang terpilih. Sementara itu grafik yang berwarna hijau merupakan prediksi jumlah kunjungan wisatawan pada tahun 2020. 


\section{SIMPULAN}

Metode prediksi dengan tingkat kekuratan yang baik untuk meramalkan jumlah kunjungan wisatawan mancanegara ke Indonesia adalah Seasonal ARIMA dengan model $(0,1,1)(0,1,1)^{12}$. Dari model ini diprediksi bahwa jumlah kunjungan wisatawan mancanegara tahun 2020 akan melewati target yang ditetapkan oleh Kementerian Pariwisata dan Ekonomi Kreatif. Dari hasil prediksi diharapkan kepada pihak pemerintah maupun swasta agar tetap mengambil kebijakan guna mencapai target kontribusi pariwisata terhadap PDB di tahun 2024.

\section{REFERENSI}

Box, G. E. ., Jenkins, G. M., Reinsel, G. C., \& Ljung, G. M. (2016). Time Series Analysis: Forecasting and Control (5th ed.). Jhon Wiley \& Sons,Inc.

BPS. (2018). Statistik Kunjungan Wisatawan Mancanegara 2018. Badan Pusat Statistik RI.

BPS. (2020). Berita Resmi Statistik: Perkembangan Pariwisata dan Transportasi Nasional Juli 2020 (Issue 70/09/Th.XXIII).

Brida, J. G., \& Garrido, N. (2011). Tourism Forecasting Using SARIMA Models in Chilean Regions. International Journal of Leisure and Tourism Marketing, 2(2), 176-190.

https://doi.org/10.1504/ijltm.2011.0388 88

Chang, Y. W., \& Liao, M. Y. (2010). A Aeasonal ARIMA model of Tourism Forecasting: The Case of Taiwan. Asia Pacific Journal of Tourism Research, 15(2), 215-221. https://doi.org/10.1080/1094166100363 0001

Iwok, I. A. (2017). Handling Seasonal Autoregressive Integrated Moving
Average Model with Correlated

Residuals. American Journal of Mathematics and Statistics, 7(June), 16.

https://doi.org/10.5923/j.ajms.20170701 .01

Kementerian PPN/Bappenas. (2019). Rancangan Teknokratik: Rencana Pembangunan Jangka Menengah Nasional 2020-2024. https://www.bappenas.go.id/id/beritadan-siaran-pers/re/.

Kontan. (2020). Pemerintah Targetkan Sebanyak 17 Juta Wisatawan Mancanegara di Tahun 2020. https://nasional.kontan.co.id/news/peme rintah-targetkan-sebanyak-17-jutawisatawan-mancanegara-di-tahun-2020.

Kumar, M., \& Sharma, S. (2016). Forecasting Tourist In Flow In South East Asia: A Case of Singapore. Tourism and Management Studies, 12(1), 107-119. https://doi.org/https://doi.org/10.18089/t ms.2016.12111

Lewis, C. D. B. G. S. (1982). Industrial and Business Forecasting Methods.

Kent:Butterworths.

Makoni, T., \& Chikobvu, D. (2018). Modelling and Forecasting Zimbabwe's Tourist Arrivals Using Time Series Method: A Case Study of Victoria Falls Rainforest. Southern African Business Review, 22. https://doi.org/10.25159/1998$8125 / 3791$

Mulyaningsih, T. (2015). Model Generalized Space Time Autoregressive Integrated untuk Peramalan Indeks Harga Konsumen Beberapa Kota di Jawa Tengah. Universitas Padjadjaran.

Razali, N. M., \& Wah, Y. B. (2011). Power Comparisons of Shapiro-Wilk , 
Kolmogorov-Smirnov, Lilliefors and Anderson-Darling Tests. Journal of Statistical Modeling and Analytics, 2(1), 21-33. https://doi.org/doi:10.1515/bile2015-0008

Wei, W. W. . (2005). Time Series Analysis Univariate and Multivariate Methods (2nd ed.). Pearson Education, Inc.Addison Wesley.

Zakaria, S., Al-Ansari, N., Knutsson, S., \& Al-Badrany, T. (2012). ARIMA Models for weekly rainfall in the semi-arid Sinjar District at Iraq. Journal of Earth Sciences and Geotechnical Engineering, 2(3), 25-55.

\section{BIODATA PENULIS}

Aida Meimela, peneliti di Badan Pusat Statistik (BPS) Provinsi Sumatera Utara dan saat ini merupakan mahasiswa magister statistik terapan di Universitas Padjadjaran.

Id Scholar:

https://scholar.google.com/citations?user=yH RFWmgAAAAJ\&hl=en 